\title{
Development and Research of the Comprehensive Performance Test Platform of the Spindle Parts
}

\author{
Xiangjuan Bai ${ }^{1}$, Jiyuan $\mathrm{Li}^{1}{ }^{1,}$, Weidong $\mathrm{Gou}^{2}$ and Zhaoshun Liang ${ }^{1}$ \\ ${ }^{1}$ School of Mechanical Engineering, Qinghai University, Xining 810016, China; \\ ${ }^{2}$ Qinghai No.1 CNC Machine Tools Co., Ltd., Xining 810016, China \\ ${ }^{*}$ Corresponding author
}

\begin{abstract}
In order to simultaneously obtain the comprehensive performance and mechanical characteristics of spindle parts of CNC machine tools, In this paper, through analyzing the testing technology of spindle parts performance, we designed a testing platform. It considers multiple types of spindle parts and can be used for actual production. The platform can achieve online realtime measurement and analysis of the stiffness, rotary accuracy, temperature, noise and vibration of spindle parts, also realize testing and analysis of the integration of data acquisition, processing, and evaluation.
\end{abstract}

Keywords-spindle parts; testing technology; comprehensive performance testing platform; integration; mechanical characteristics

\section{INTRODUCTION}

The spindle parts is one of the important part of the highend CNC machine tools, which has an significant influence on the mechanical behavior and reliability of the machine ${ }^{[4]}$.At present, the dynamic testing and evaluation of spindle comprehensive performance in domestic machine tool industry has not yet formed a systematic and integrated testing technology. Static and a few dynamic parameters of the test are mostly confined in enterprises, also contain universities and research institutes, but there is still some distance from engineering applications.

Based on the above situation, through the analysis and research of the comprehensive performance parameters of the spindle parts in the paper, the testing technology of performance parameter is proposed and the test platform of comprehensive performance parameters is designed and developed. Because the test platform is used for testing and analyzing the spindle unit and the assembly body of spindle box parts, so the spindle assembly and operation are more suitable the actual situation. Research and development on a high-end $\mathrm{CNC}$ machine tool spindle unit comprehensive performance testing system, which is integrated and can be used for production site, is of great significance to improve the technical level and the quality of product processing for China's manufacturing industry.

\section{Test ItEMS AND Testing PRINCIPLES}

\section{A. Test Items and Test Object}

According to national standards and design requirements, the vibration, temperature, rotary accuracy and other parameters can be measured and analyzed for the high-end $\mathrm{CNC}$ machine tool spindle unit during spindle operation on the platform. Testing object includes motorized spindle, mechanical spindle, Variable speed drive spindle box assembly with box .Several main technical data on the test platform are showed in TABLE I.

TABLE I. TEST ITEMS OF SPINDLE PARTS

\begin{tabular}{|l|c|c|c|c|c|c|c|}
\hline $\begin{array}{c}\text { Test } \\
\text { items }\end{array}$ & $\begin{array}{c}\text { Rotary } \\
\text { accurac } \\
\text { y }\end{array}$ & $\begin{array}{c}\text { Stiffnes } \\
\text { s }\end{array}$ & $\begin{array}{c}\text { Vibratio } \\
\text { n }\end{array}$ & $\begin{array}{c}\text { Temperat } \\
\text { ure }\end{array}$ & $\begin{array}{c}\text { Broach } \\
\text { force }\end{array}$ & $\begin{array}{c}\text { No- } \\
\text { load } \\
\text { power }\end{array}$ & Noise \\
\hline $\begin{array}{c}\text { Mechanic } \\
\text { al spindle }\end{array}$ & $\sqrt{ }$ & $\sqrt{ }$ & 0 & $\sqrt{ }$ & $\sqrt{ }$ & $\sqrt{ }$ & $\sqrt{ }$ \\
\hline $\begin{array}{l}\text { Motorize } \\
\text { d spindle }\end{array}$ & $\sqrt{ }$ & $\sqrt{ }$ & $\sqrt{ }$ & $\sqrt{ }$ & $\sqrt{ }$ & $\sqrt{ }$ & $\sqrt{ }$ \\
\hline $\begin{array}{l}\text { Spindle } \\
\text { box } \\
\text { assembly }\end{array}$ & $\sqrt{ }$ & $\sqrt{ }$ & $\sqrt{ }$ & $\sqrt{ }$ & $\sqrt{ }$ & $\sqrt{ }$ \\
\hline
\end{tabular}

Note: $\sqrt{ }$ for the necessary test items, $\bigcirc$ for the selected test items

\section{B. Test Method}

\section{1) Rotary accuracy}

In the idling process, testing the spindle rotary accuracy through the eddy current sensor measures the displacement variation of check rod axis line. Through collecting the data, frequency spectrogram is simulated at different rotational speeds. Location of measuring points ${ }^{[1]}$ :In the testing process, the two sets of displacement changes in the direction of the two perpendicular of spindle and end face beating are needed to measure by the Eddy current sensors, So it is necessary to be measured the five test points simultaneously.as shown in FIGURE I.

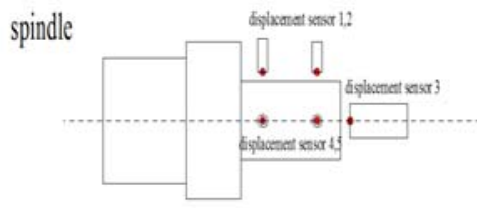

FIGURE I. THE POSITION DISTRIBUTION OF THE TESTPOINT OF THE ROTARY ACCURACY

\section{2) Vibration}

Testing the spindle vibration when the spindle is running, the axial and radial displacement of the motorized spindle are measured and recorded by two displacement sensors 
respectively. Through collecting the data, frequency spectrogram is simulated .Finally, the vibration value of the motorized spindle is measured at different rotational speeds. The test points are located at the position where the cutter and workpiece are supported by the motorized spindle ${ }^{[2]}$. Selecting a and d points, as shown in FIGURE II-A.

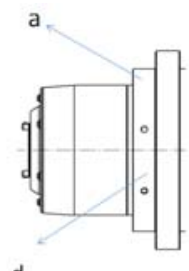

A

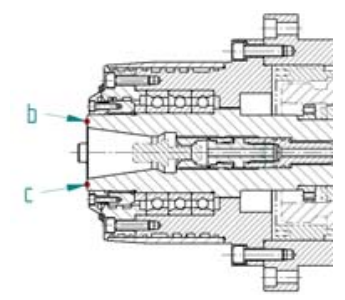

B
FIGURE II. POSITION OF VIBRATION AND TEMPERATURE TESTPOINT

\section{3) Temperature}

In the testing process, the temperature changes of the spindle end face are monitored at different speeds, and obtaining the temperature rise curve. Because the heat source of the spindle comes mainly from heat of bearings and rotor, at the same time the front end face of the spindle is the nearest part from the front bearing, which is the closest temperature to the heating temperature of the spindle, the front end face is selected as the testpoint. $\mathrm{b}$ and $\mathrm{c}$ points are illustrated in FIGURE II-B .

\section{4) Noise}

Noise measurement of spindle can be directly measured by noise sensors. Through the data collected to determine whether the spindle noise value is in the national standard range, thereby ensuring the normal operation of the machine tool. The measuring point position is arranged along the machine periphery, Generally taking machine front, back, both sides of a total of four positions as standard measuring point position ${ }^{[3]}$.

\section{5) No-load power}

No-load power can be directly tested through manual recording for data acquisition.

\section{6) Broach force}

In the process of using the motorized spindle, it is necessary to test the a single force of broach. During the testing process, broach force can be directly measured by broach force measuring tools, which is installed on the spindle. When testing, the pressure sensor is arranged between the handle and the broach rod.

\section{7) Hydraulic leakage}

The hydraulic leakage of the spindle will lead to the problem of no keeping the pressure which leads to the invalidation of the spindle system. In this paper, the hydraulic leakage testing device is used.

\section{8) Stiffness}

The stiffness of the spindle reflects the ability of the machine to resist external loads. Through the testing of stiffness, the maximum load can be obtained when the spindle is machined. The static stiffness of the spindle has a great influence on the static stiffness of the whole machine. Under the load F, the tool and the spindle will produce displacement respectively. During the testing process, using he load bar to replace the tool. When the spindle is static, applying force to the load bar through the loading device, during applying force process, to measure the force simultaneously by pressure sensors connected with loading device. Removing load bar and installing the test bar .the axial and radial displacement of test bar axis line is measured and recorded by two displacement sensors installed around the test bar, finally, the static stiffness values of the spindle under different loading forces are measured, and the quantitative data and curves of stiffness are obtained. set position of force point and testpoint: (1)When measuring the radial stiffness, the force point is near the limit position of the load bar extended end, as shown F1 in FIGURE III. Testpoint and force point about the axis line symmetry, see B1 in FIGURE III.(2)When measuring the axial stiffness, force point should near by the axial line, see F2 in FIGURE III, testpoint located at the edge of the limit position of test bar' axial end face, see B2 in FIGURE III.

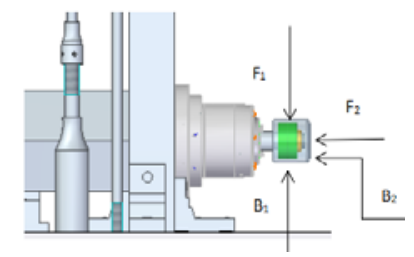

\section{FIGURE III. POSITION OF FORCE POINT AND TESTPOINT}

\section{DESIGN OF TEST PlATFORM}

In order to meet the requirements of automated and integrated online real-time measurement and analysis of test platform, according to the test items and the test methods, Spindle unit test platform schematic as shown in FIGURE IV. The PLC control the digital quantity and analog quantity of the performance index, which is related to acquisition operating tables and functional unit of the system, and do the Logic calculation of IPC(Industrial Personal Computer) parameter setting ,besides output the control command to control function unit and auxiliary device, loading device. The operating table is a manual operating platform. IPC is a man-machine interactive window, which is used for setting the system parameters and test parameters, displaying the test status and data, displaying the system failure and operational error alarm, and so on. The computer data acquisition system is composed of industrial control computer and control software. According to the set test procedures, the computer collects the relevant performance index signal of each test phase, and records the test results to generate test reports. The original test data can be stored and output for later query and management.

According to the measuring principle of above test platform, The test platform is composed of temperature test, vibration test, noise test, stiffness test and rotation accuracy test, therefore, the design of high speed motorized spindle test platform should include: (1) Fixing device for motorized spindle. (2) Fixing device for temperature sensor, acceleration sensor and noise sensor. (3) Loading device and its fixing rack. 
Above all, The test platform includes loading system, T type worktable, base, control system, Hydraulic system, cooling and lubricating system and data acquisition device etc.

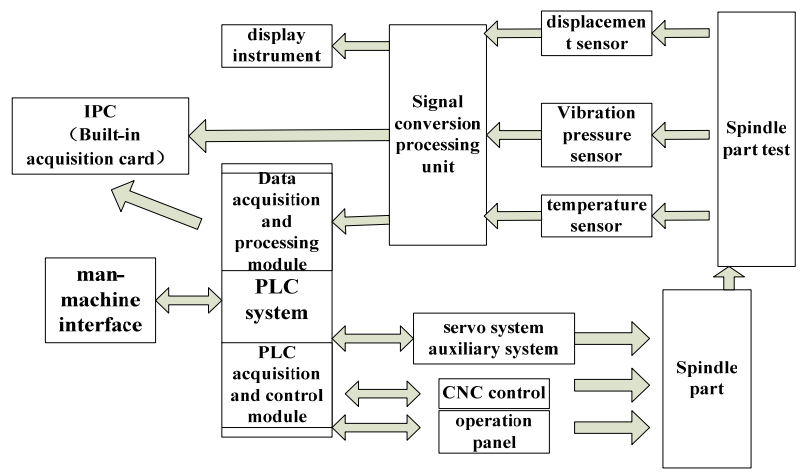

FIGURE IV. MEASUREMENT PRINCIPLE OF THE TEST PLATFORM

Loading device: For the testing of motorized spindle, in this paper in order to better simulate the actual process of engineering, installing the loading device on the crossbeam of portal frame is designed from the point of contact loading, which is used to simulate the actual cutting force in cutting process and load the loading rod. To load in axial and radial direction in the process of loading. In this test platform, the SMC cylinder with good performance is used to load the loading bar. So the system mainly includes portal frame, cylinder assembly, vertical and horizontal conversion head and $\mathrm{V}$ block device, etc. The portal frame is fixed on the $\mathrm{T}$ worktable, and its bottom is connected with trapezoidal screw to achieve the effect of front and back movement; According to the 45 degree incline principle, the vertical and horizontal conversion head used to test the spindle radial and axial stiffness through rotated 90 degrees in the $\mathrm{T}$ slot to achieve conversion of the spindle axial and radial direction;

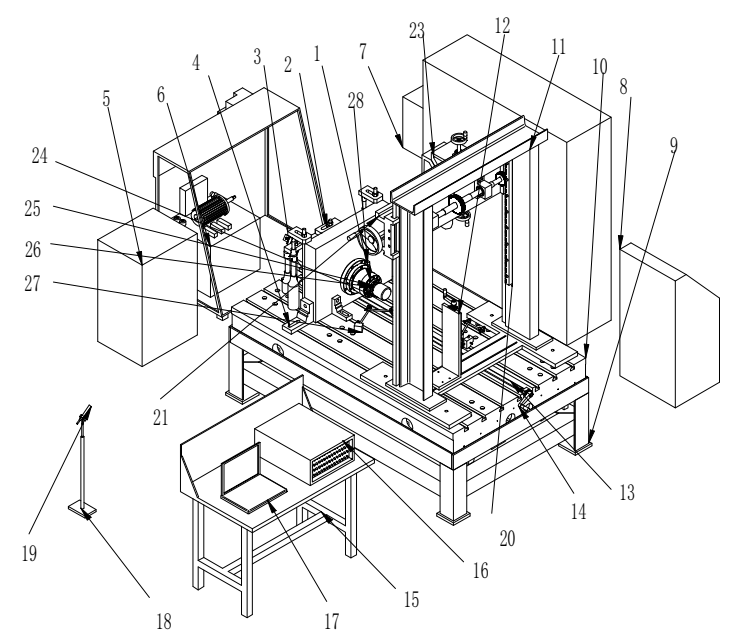

1spindle; 2 spindle box;3 pressplate; 4 bending plate $; 5$ cooling and lubricating device; 6 hydraulic pressure station; 7 control cabinet; 8 operation panel; 9 the base;10 T type worktable; 11 portal frame; $12 \mathrm{Z}$ type collecting device; 13 base screw; 14 base screw handle; 15 desk; 16 LMS acquisition

instrument; 17 computer; 18 noise sensor support;19 noise sensor;20 straight rack for beam;21 beam;22 chute board;23 vertical and horizontal conversion head;24 sleeve; 25 bore-hole;26 load bar;27 magnetic stand;28 three axis acceleration sensor;

FIGURE V. TESTING PLATFORM
Fixing device for sensor, In order to ensure that the test axis of the sensor in the $\mathrm{X}, \mathrm{Y}$ direction coincides with the axis of the spindle, fixing device for sensor used the $Z$ type device. The spindle rotary accuracy is tested by five displacement sensors. Two mutually perpendicular displacement sensors installed on the proximal end and the far end of the test rod and another displacement sensor are arranged on the end surface of the far axle end. They can be freely moved in six directions to satisfy testing to the test rod with different sizes by the linear guide rail and the bottom $\mathrm{T}$ slot. Vibration acquisition device includes three acceleration sensors installed near the front bearing seat in the front of the spindle end; Temperature acquisition directly tests the temperature inside the taper hole of spindle by using infrared temperature sensor, although there is a certain error, within the allowable error range; Placing the noise sensor parallel to the spindle height at 1 meters outside the base; So as to achieve the data collection of the stiffness, vibration, rotary accuracy, temperature, noise and other parameters of the spindle part.

During the test, as long as the spindle unit and the spindle box assembly are completely fixed on the T type worktable and connected with the control system, cooling lubrication system and other equipment, the online real-time measurement and analysis can be realized. The diagram of detailed design structure is shown in FIGURE V.

\section{AnAlysis AND EVAluation OF Test PlatForm}

\section{A. Portal Frame Mechanism}

Portal frame is the core component of the entire test platform. The schematic diagram of the structure is shown in FIGURE VI.

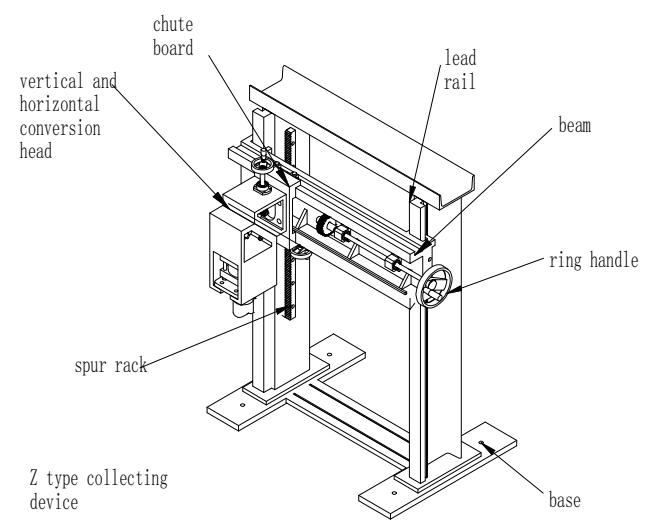

FIGURE VI. PORTAL FRAME MECHANISM

The framework of the portal frame is made of $22 \# \mathrm{~B}$ channel, the welded steel structure, one side of it installed a hard guide rail, The whole beam can move up and down on the hard rail through meshing drive by straight rack and gear and can be controlled by ring handle. When moving to a certain position, It can use the board to clamp and fix. The chute board installed on the beam can move right and left on it. The transmission principle is same as the beam's, the difference is that the chute board is fixed by a clamping bolt block. According to the 45 degree incline principle, the vertical and horizontal conversion head can achieve the conversion of axial 
and radial load, the cylinder is installed on end, the other end is fixed on the chute board, along with the chute board to move left and right. The lower end of the portal frame is welded on the chute board, which is installed on the T worktable, and it can move back and forth, using the T type bolt to clamp and fix when moving to a certain position. In the middle of the chute board installed a $\mathrm{Z}$ acquisition device, which can be realized by $\mathrm{T}$ slot move back and forth in the middle of chute board, it also can move up and down itself. Thus, the whole portal frame can realize the movement in many directions, achieving loading and collecting data for different kinds of spindle.

\section{B. Theoretical Analysis of Portal Frame Mechanism}

\section{1) Theoretical analysis}

There are two kinds of vibration in the process of using the portal frame, forced vibration and self-excited vibration. The dynamic characteristic is the ability to resist the forced vibration and self-excited vibration. Since the portal frame may not only produce forced vibration but also produce self-excited vibration, The designed portal frame should have good resistance to these two types of vibration to meet the needs of the test platform. Therefore, it is necessary to establish the motion differential equation of the portal frame system.as follows:

$$
[M]\left\{x^{\prime \prime}\right\}+[C]\left\{x^{\prime}\right\}+[K]\{x\}=\{F(t)\}
$$

This equation is the dynamic equation of the elastic body, which is used to solve the dynamic problems of elastic body by finite element method. The excitation of the portal frame system is generated during the loading process of the electric spindle. In the formula,[M] is the mass matrix; $[\mathrm{C}]$ is damping matrix ; $[\mathrm{K}]$ is stiffness matrix; $\{\mathrm{x}\}$ is the displacement vector; $\{\mathrm{F}(\mathrm{t})\}$ is the force vector; $\left\{\mathrm{x}^{\prime}\right\}$ is the velocity vector; $\{x "\}$ is acceleration vector. When the amount of time $t$ is ignored, there will be no coupling term of acceleration and velocity, and the equation is simplified to the static equation as follows:

$$
[K]\{x\}=\{F\}
$$

\section{2) Finite element analysis}

\section{a) Stiffness analysis of portal frame mechanism}

Stiffness analysis is an essential part of the static characteristics analysis of an object ${ }^{[5]}$. Due to the beam and the chute board are the core components of the portal frame, the stiffness analysis of the portal frame is a comprehensive analysis of the rigidity of the beam and the chute board. Because the portal frame loaded in radial and axial two directions, we should exert force on the piston rod end of the cylinder under two states position. According to Newton's third law, the direction of force perpendicular to the end face of the cylinder and face to it, its size is $12 \mathrm{KN}$, besides, we need to do the stiffness analysis for the beam under gravity. After analysis, the following results are obtained:

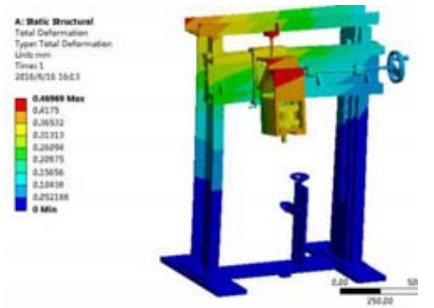

A. RADIAL STIFFNESS

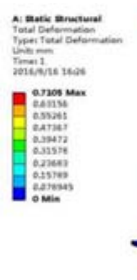

B. AXIALL STIFFNESS

FIGURE VII. TOTAL DEFORMATION OF STIFFNESS

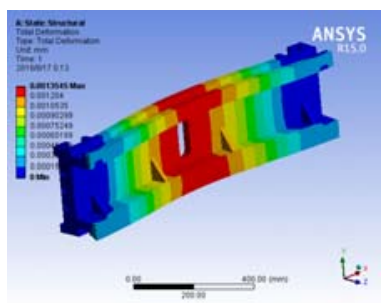

A. TOTAL DEFORMATION
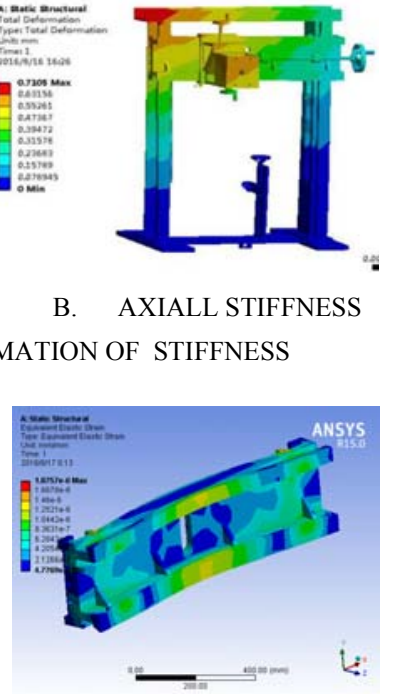

B. EQUIVALENT STRAIN
FIGURE VIII. THE ANALYSIS OF THE BEAM

The results of the analysis are summarized in Table II :

TABLE II. ANALYSIS RESULTS

\begin{tabular}{|c|c|c|c|}
\hline Items & $\begin{array}{c}\text { Max total } \\
\text { deformation }(\boldsymbol{\mu m})\end{array}$ & $\begin{array}{c}\text { Max equivalent } \\
\text { strain }(\boldsymbol{\mu m})\end{array}$ & $\begin{array}{c}\text { Max equivalent } \\
\text { stress }(\boldsymbol{M P a})\end{array}$ \\
\hline Radial stiffness & 470 & 0.63 & 127 \\
\hline Axial stiffness & 710 & 0.37 & 75 \\
\hline Beam Stiffness & 1.35 & $1.87 \times 10-3$ & 0.29 \\
\hline
\end{tabular}

We can get conclusions from the chart and table :(1)The maximum value of radial stiffness total deformation is in the upper part of the vertical and horizontal conversion head, which is less than allowable stress of portal frame; The equivalent elastic strain value is very small, within the allowable range. From the chart we can ensure that the main position of strain is located at the bolt which is used to fix the vertical and horizontal conversion head. The maximum stress is much less than the yield strength of stainless steel $310 \mathrm{MPa} .(2)$ The maximum value of axial stiffness total deformation is in the top of the portal frame, Similarly, in the allowable range; The maximum value of equivalent elastic strain and equivalent stress are located at the root of the portal frame, where is the more dangerous area. we can consider using the ribbed plate to reinforce it .Besides ,The maximum stress is less than yield strength of Q235 235MPa.(3)The stiffness of the beam meets the actual needs, but can be seen from the chart, the maximum displacement is located in the middle of it. Because of the large span lead to the small stiffness of the middle part. Besides, it also needs to bear the gravity of the chute board and vertical and horizontal conversion head, so we should strengthen the stiffness of the middle part.

\section{b) Modal analysis of portal frame mechanism}

The portal frame is a welding part, and its rigidity is poor, which may affect the accuracy of testing, at the same time, In the process of testing, there exists vibration instability. In order 
to reduce the vibration during the loading process of the portal frame, it is very important to carry out the modal analysis. To verify the performance of the designed portal frame, the modal analysis of the portal frame is carried out by using ANSYS Workbench. We use the most common Stochastic Subspace Method ${ }^{[4]}$.The modal analysis is mainly composed of five steps: modeling, loading, solving, extending mode and postprocessing. After analysis the simplified model, the first four order modes of vibration are as follows:

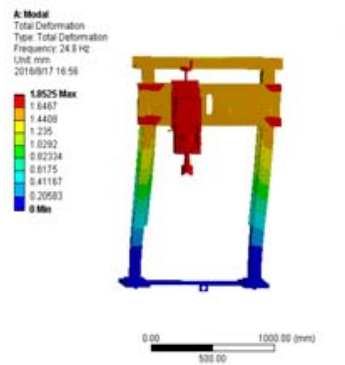

A. FIRST ORDER

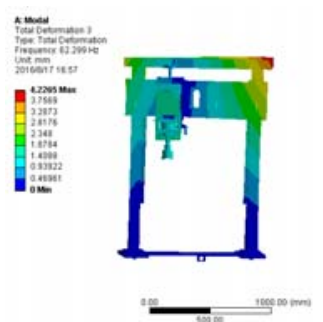

C. THIRD ORDER

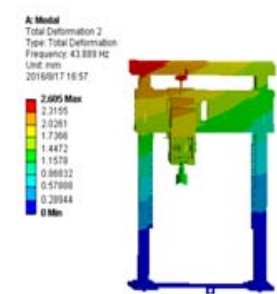

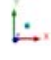

B. SECOND ORDER

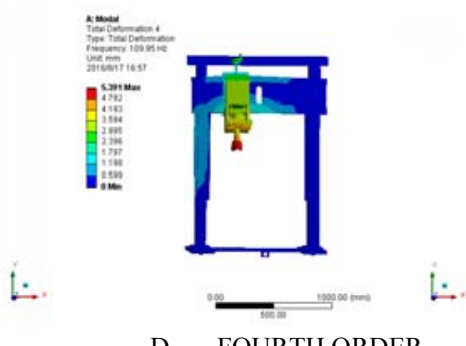

D. FOURTH ORDER
FIGURE IX. THE INITIAL FOURTH ORDER VIBRATION MODE

A detailed description is given in Table Table III:

TABLE III. MODAL ANALYSIS RESULTS

\begin{tabular}{|c|c|c|c|c|}
\hline Order & $\mathbf{1}$ & $\mathbf{2}$ & $\mathbf{3}$ & $\mathbf{4}$ \\
\hline $\begin{array}{c}\text { Max } \\
\text { deformation(mm } \\
\text { ) }\end{array}$ & 1.85 & 2.6 & 4.22 & 5.39 \\
\hline Frequency & 24.8 & 43.889 & 62.299 & 109.95 \\
\hline $\begin{array}{c}\text { Mode of } \\
\text { vibration }\end{array}$ & $\begin{array}{c}\text { parallel } \\
\text { move }\end{array}$ & $\begin{array}{c}\text { first order } \\
\text { bending }\end{array}$ & $\begin{array}{c}\text { second order } \\
\text { bending }\end{array}$ & $\begin{array}{c}\text { first order } \\
\text { swing }\end{array}$ \\
\hline
\end{tabular}

As can be seen from the above table, the first order vibration mode is relatively small, mainly rigid body vibration, whose effect is not large. The maximum deformation displacement is $\mathrm{X}$ direction of the vertical and horizontal conversion head. we can strengthen its stiffness and reduce the quality. The frequency of the other three order models increases, and the deformation gradiently distributes from the bottom to the top. The vibration of external load affects the vibration of the whole portal frame, after investigation, The frequency of this integrated test platform is concentrated between $30-40 \mathrm{HZ}$, so the portal frame can effectively avoid the resonance.

From the modal analysis, combined with the actual situation, the whole organization to do a more accurate analysis to determine the structure of the natural frequency and formation. The mechanism can effectively avoid the occurrence of resonance, it also has excellent dynamic characteristics. The stiffness analysis shows that both the deformation and yield strength of the whole mechanism can meet the requirements of static load and have good static characteristics.

\section{CONCLUSION}

In this paper, Based on the research of the testing technology of comprehensive performance of spindle, designed a test platform, which is considering multiple types of spindle unit of the high-end $\mathrm{CNC}$ machine tool. It can realize the integration and automation of testing, so as to guide the production site. According to the proposed test principle, On this platform we can achieve online real-time measurement and analysis of the stiffness, rotary accuracy, temperature, noise and vibration of a variety of spindle, and it also can realize the integration and automation of data acquisition, processing, analysis and evaluation, for the spindle optimization design and troubleshooting and other follow-up work to provide a reliable basis.

\section{ACKNOWLEDGMENT}

This work is supported by Key Project of Technology Department of Qinghai Province of China grants 2015-GXQ18A, 2015-GX-Q09.I thank Professor Jiyuan LI, Senior engineer Weidong GOU and Zhaoshun LIANG for critical reviews.

\section{REFERENCES}

[1] GBT 17421.2-2000. Test code for machine tools Part 2:Deter-mination of accuracy and repeatability of positioning umerically controlled axes[S].

[2] GB/T 16768-1997. Metal-cutting machine tools-Measurem-ent method for vibration[S].

[3] GB/T 16768-1997. Metal-cutting machine tools-Measurem-ent method of sound pressure level[S].

[4] Wang Chao,Wang Jin.Mechanical reliability engineering[M]. Beijing:Metallurgical Industry Press, 1998.

[5] Zhou Dashuai.Research on the comprehensive performance test and some key technologies of high speed motorized spindle [D]. Beijing Industrial University,2011. 